\title{
Mitos, creencias, valores: cómo hacer más «científica» la ciencia; cómo hacer la «realidad» más real
}

\author{
Myths, beliefs, values: how to make science more \\ «scientific»? how to make reality more «real»?
}

\author{
Eulalia PÉrez Sedeño \\ Instituto de Filosofía - CCHS, CSIC
}

\begin{abstract}
Resumen. Los efectos del desarrollo del feminismo en la ciencia pueden apreciarse tanto desde un punto de vista sociológico, como epistemológico. A lo largo de este artículo, se abordará el tipo de articulaciones que el feminismo ha elaborado en los procesos ligados a la producción del conocimiento científico, así como al conocimiento en sí. Eso ha sido posible gracias a las diferentes olas del feminismo y su contribución en los procesos de construcción del conocimiento, en la accesibilidad de las mujeres a las instituciones y determinadas áreas o en la propia elaboración de nuevos modelos de referencia. Pero la crítica feminista también es fundamental no sólo a la hora de abordar disciplinas científicas que se articulan en torno a fuertes determinismos, como es el caso del biológico, sino también aportando nuevos enfoques filosóficos con los cuales poder dar cuenta de la ciencia de un modo más científico y real.
\end{abstract}

Palabras clave: epistemología feminista, filosofía de la ciencia, axiología, objetividad, neutralidad
Abstract. The development of the feminism in science can be appreciated so much from both sociological and epistemological views. Along this paper, it will be explored the type of articulations that the feminism has elaborated in the processes tied to the production of the scientific knowledge, and its own contents. The three different waves of the feminism contributed to the processes of construction of scientific knowledge, to the accessibility of women to the institutions or determined areas and to the elaboration of new models. But the feminist critics also became fundamental not only to overcome scientific determinisms, as biological one, but also to give new philosophical approaches to make possible a more scientific and real science.

Key words: feminist epistemology, philosophy of science, axiology, objectivity, neutrality.

¿Qué ha supuesto la irrupción del feminismo en la ciencia? ¿Ha producido algún cambio? Estas cuestiones pueden entenderse de diferentes maneras. Por ejemplo, desde un punto de vista puramente sociológico pueden entenderse como preguntas acerca de los cambios producidos en la comunidad científica 
(entendida ésta en sentido amplio). Pero también pueden referirse a si las reflexiones realizadas desde el feminismo han provocado cambios en los contenidos de las teorías y prácticas que conforman las diferentes disciplinas científicas o si tal irrupción ha supuesto variaciones en la reflexión sobre la ciencia y la concepción que de ella se tiene. Para responder a lo primero, basta con hacer un estudio empírico de la situación de las mujeres en las instituciones científicas de todos los niveles. Responder a las otras supondría hacer un examen exhaustivo de cada una de las disciplinas científicas y sus componentes teórico-prácticos y de la concepción (o concepciones) emanadas de la historia y la filosofía de la ciencia. Como por razones obvias no podemos hacer aquí un recorrido exhaustivo, en lo que sigue intentaremos exponer, brevemente y de manera general, algunos de los cambios experimentados que contribuyen a una mejora sustancial de nuestro conocimiento.

\section{Mitos y creencias}

Siendo como es el feminismo una ideología social y política, y considerándose la ciencia, como lo ha sido hasta hace bien poco, el producto de la aplicación de la razón a la realidad, ajeno a interferencias extrañas, no resulta raro que el encuentro entre ambos haya tardado en producirse. Y no porque no hubiera razones: la ciencia ha servido, durante siglos, como justificación y fundamento de la subordinación sociopolítica, a veces sometimiento, de las mujeres.

Tal subordinación aparece en los mitos fundacionales de la cultura occidental. Los mitos son muy importantes, pues perfilan el papel que desempeñamos en un universo misterioso. En especial, los que tratan sobre la creación son fundamentales porque expresan las creencias que tiene una cultura sobre la naturaleza de la humanidad, sus orígenes y la finalidad de su existencia, a la vez que especifican las relaciones existentes entre las cosas. En definitiva, revelan gran parte de nuestros valores elementales.

En la Biblia, en la versión de la creación que aparece en el capítulo 2 del Génesis, se dice: «De la costilla que el Señor Dios había tomado del hombre, formó una mujer y la llevó ante el hombre. Entonces éste exclamó: "Esta vez sí que es hueso de mis huesos y carne de mi carne. Ésta será llamada mujer, porque del varón ha sido tomada"» (2:22-23). No obstante, antes, en el Capítulo 1 del mismo libro se dice: «Hagamos al ser humano a nuestra imagen, a semejanza nuestra, y mande en los peces del mar y en las aves de los cielos, y en las bestias y en todas las alimañas terrestres, $\mathrm{y}$ en todas las sierpes que serpean por la tierra. Creó, pues, Dios al ser humano a imagen suya, a imagen de Dios lo creó, varón y mujer los creó» ${ }^{1}(1: 26-27)$. Es decir, se crea a la vez al

\footnotetext{
1 La cursiva es mía.
} 
hombre y a la mujer, lo que no supone subordinación ni inferioridad alguna. Y, sin embargo, la tradición cristiana optó por la versión que relega a la mujer como creada temporal, física y metafísicamente después que el varón ${ }^{2}$.

El otro gran mito conformador de la cultura occidental, tal y como lo cuenta Hesíodo en su Teogonía, nos presenta a Pandora, creada por orden de Zeus para castigar a la raza humana por el engaño que le hiciera Prometeo, tras perpetrar el robo del fuego para dárselo a los hombres. Hefestos, ayudado por Palas Atenea, la dota de una serie de cualidades otorgadas por los otros dioses como belleza, gracia, habilidad manual y persuasión, pero también capacidad de seducción y de manipulación y le confiere un corazón en el que anidaba la mentira. Enviada a la Tierra con una caja o jarra que no debía abrir, pues contenía todos los males, Epimeteo, hermano de Prometeo, se casa con ella a pesar de las advertencias del hermano, que esperaba algún mal proveniente de Zeus. Movida por la curiosidad, Pandora abre la caja y los males se esparcen sobre la humanidad. Así, Pandora y Eva (cuya curiosidad le hace atreverse a comer la manzana del árbol del conocimiento del bien y del mal) conforman los estereotipos occidentales de la feminidad: son las mujeres quienes provocan la perdición de la humanidad, sin que la característica que las mueve, la curiosidad, adquiera una ligera connotación positiva, sino una carga completamente negativa. No resulta extraño que, a lo largo de la historia, se les negara/prohibiera a las mujeres la posibilidad de ejercitar esa cualidad, en su sentido positivo, tan necesaria para el conocimiento.

Pero no sólo los mitos revelan y conforman nuestros valores y estereotipos del imaginario de mujeres y hombres. También la ciencia y la filosofía han contribuido de manera fundamental. Platón, en el Timeo, explica cómo el Demiurgo crea un mundo en el que originalmente no hay mujeres. Tras dividir la mezcla con la que constituye el universo en almas iguales en número a las estrellas, asigna un alma a cada estrella; luego, implanta un alma en cada cuerpo de varón (el universo original platónico es masculino) y da a cada hombre sensaciones y emociones. Todos los hombres eran creados igualmente perfectos, pero sus destinos estaban determinados por su capacidad de manejar sus emociones y sensaciones: «si las dominaban, podían vivir virtuosamente, pero si eran dominados por ellas, no lo harían» (Timeo, $42 \mathrm{~d}$ ). Si un hombre dominaba sus sensaciones gobernándolas mediante su intelecto, al morir volvería a su estrella para tener una existencia santa. Pero si no refrenaba sus apetitos, si era incapaz de controlar sus emociones o los deseos de su cuerpo, si se dejaba llevar por sus pasiones, se reencarnaría en una mujer: «en su segundo nacimiento, se convertiría en una mujer y si, en ese estado del ser no desistiera del mal, a continuación se transformaría en alguna bestia que se le asemejara en la naturaleza maligna que había adquirido» (Timeo, 42 b-c).

\footnotetext{
${ }^{2}$ Hasta el punto de que muchos cristianos desconocen la existencia de las dos versiones.
} 
Por su parte, Aristóteles, el padre de la biología, no sólo consolidó «científicamente» la subordinación de las mujeres, sino que las condenó de forma «natural». En efecto, el calor es el principio fundamental y de perfección: «Lo que por naturaleza tiene menor proporción de calor es más débil» ${ }^{3}$. La naturaleza pretende crear el ser más perfecto formado, pero la mujer es más fría que el hombre y, por tanto, menos perfecta. Al tener el varón calor en alto grado, es capaz de cocer la materia, lo que destruiría el feto. Sólo un ser incapaz de cocer toda la materia puede nutrir el feto y no destruirlo. Por tanto, la frialdad de la mujer, su imperfección, es necesaria para perpetuar la «raza» ${ }^{4}$. Además, la frialdad produce diferencias fisiológicas y psicológicas, que en Aristóteles son defectos. Así, las hembras son de menor tamaño, más débiles, menos musculosas, menos compactas y con un cerebro menor y menos desarrollado; psicológicamente son más celosas, quejumbrosas, desvergonzadas, mentirosas y engañosas ${ }^{5}$.

Las características asignadas a las mujeres, asociadas a la esfera privada y del cuidado y el sentimiento, han arraigado en formas de estereotipos sexuales, presentes en nuestras vidas desde el momento en que nacemos: asocian a los varones con cualidades tales como las de racionalidad, dominación, independencia, frialdad y objetividad, mientras las mujeres se asocian con la irracionalidad, pasividad, dependencia, ternura, emotividad y subjetividad. Se considera que estas características «femeninas», opuestas a las «masculinas» y minusvaloradas, son un obstáculo para la prosecución de una carrera científica, ya que las cualidades necesarias para hacer ciencia son las «masculinas». Estas ideas, con un grado mayor o menor de desarrollo y más o menos «apoyadas por los hechos», conformaron las ideas cientificas sobre las mujeres hasta bien entrado el siglo XX.

\section{Hechos ¿sin valores?}

En los años sesenta y en los países anglosajones, sin embargo, surge con gran ímpetu renovado ${ }^{6} \mathrm{el}$ interés del feminismo por la ciencia (y posteriormente la tecnología). El feminismo de los años sesenta y setenta partía del supuesto de que los diferentes logros en el conocimiento, y en especial en la ciencia, no se

3 Todas estas ideas se pueden encontrar a lo largo de las obras biológicas de Aristóteles, pero, fundamentalmente, en Sobre la generación de los animales y en Investigaciones sobre los animales

${ }^{4}$ Lo que hoy denominaríamos la especie humana.

5 Para un examen más exhaustivo de las ideas aristotélicas sobre las mujeres, véase, por ejemplo, Campese, Manuli y Sissa (1983), Tuana (1993), Pérez Sedeño (1997) o Gómez (2004).

6 Como indicaremos más adelante, a finales del s. XIX hay un movimiento parecido, coincidiendo con el sufragismo. 
debían a características innatas: si las mujeres no habían alcanzado los niveles de conocimiento de los varones era debido a causas externas y circunstanciales, a su socialización y educación (o más bien falta de esta última) a lo largo de la historia. Prueba de ello son las diferencias existentes entre las sociedades que educan a sus mujeres y las que no. Y como una de las características generales del feminismo es avanzar propuestas sociales y políticas que conduzcan a la plena igualdad de las mujeres, la educación fue considerada un área de actuación fundamental y preferente. La pregunta clave a responder era por qué las chicas optaban menos por las ciencias que los chicos. Se analizó cómo se enseña la ciencia y la tecnología desde la escuela y el contenido de los diferentes currículos, a la vez que se diseñaban distintas y variadas estrategias para alentar el estudio y trabajo de las niñas y mujeres en las ciencias. Pero también se modificaron los libros de texto u otras actividades escolares (que presentan imágenes y actividades estereotipadas, lenguaje sexista, etc.), a la vez que se analizaban actitudes y expectativas, tanto del profesorado como del alumnado, sacando a la luz su carácter discriminatorio en muchas ocasiones, y se constataba la necesidad de proveer de modelos de referencia para las mujeres que quieran estudiar o dedicarse a la ciencia ${ }^{7}$.

La situación en la mayoría de los países occidentales, como el nuestro en el que la educación es obligatoria y gratuita desde los 3 a los 16 años e igual para niñas y niños, está cambiando a pasos agigantados. En la actualidad, la tasa de alfabetización es de $97,7 \%{ }^{8}$. Por lo que se refiere a las tasas netas de escolarización por grupos de vida, en el curso 2006-2007 era del 95,8\% en el grupo de niños de tres años y el 100\% en el grupo de 4 a 16 años, disminuyendo a medida que se avanza en edad ${ }^{9}$. La distribución por sexos presentaba las siguientes características. Por ejemplo, en el curso 2004-2005, en la enseñanza obligatoria, es decir en educación primaria y enseñanza secundaria obligatoria, las mujeres constituían el 48,5\% frente al 51,5\% de varones, aunque esa diferencia se debe a la estructura poblacional. Sin embargo, esa situación se invierte en las enseñanzas no obligatorias, es decir, conjuntamente en el bachillerato y la formación profesional (las mujeres aquí son el 51,2\%), aunque es interesante observar que las mujeres constituyen el $55 \%$ en los estudios de bachillerato, necesarios para pasar a la Universidad, disminuyendo al 45,8 en los ciclos formativos de grado medio. Hay que señalar, además, que las mujeres tienen un mayor nivel de escolarización, ya que a los 16 años la tasa de escolaridad femenina es del 90,7\% mientras que la de los hombres es del $85 \%$. Por otro lado, el índice de éxito es siempre mayor en las mujeres: el $78 \%$ acaba la secundaria, frente al $63,1 \%$ de los hombres y el $52,8 \%$ de mujeres obtienen el título de bachillerato frente al 36,2\% de los hombres.

${ }^{7}$ Los trabajos sobre género y educación son muchísimos, con foros de discusión nacionales e internacionales, revistas plenamente consolidadas en la comunidad, etc.

8 Informe Sobre el Desarrollo Humano, PNUD, 2005.

9 Datos Básicos de la Educación en España en el curso 2006-2007, MEC. 
En el curso 2005-2006, las mujeres matriculadas en la Universidad española alcanzaban el 54,4\% frente al 45,6\% de varones, licenciándose un $60,6 \%$ de mujeres, frente al $39,4 \%$ de varones del total de licenciados universitarios. De hecho, las mujeres son mayoría prácticamente en todas las carreras universitarias excepto en las ingenierías (en matemáticas y físicas, aún no han llegado al 50\%, pero lo rozan). También aquí la tasa de éxito es mayor entre las mujeres: el $60,6 \%$ de las personas que se licencian o gradúan son mujeres. Pero cuando comienza la carrera profesional académica o investigadora las cifras comienzan a descender: si bien las mujeres constituyen el 50,5\% de personas que inician sus estudios de doctorado, sólo los culminan el 47,8\%, constituyen el $35 \%$ del profesorado universitario permanente y tan sólo el $13 \%$ del total de personas que ostentan una cátedra ${ }^{10}$.

Aún es peor en los puestos de toma de decisiones o en las instituciones de más prestigio, en los rectorados, como directoras de los Organismos Públicos de Investigación (OPIs), etc. Por ejemplo de los seis OPIs que en mayo de 2008 dependían del Ministerio de Ciencia e Innovación, ninguno está dirigido por una mujer. El número de rectoras (4 entre 72), es testimonial, igual que lo son las mujeres en las Reales Academias: en la Real Academia de la Historia, sólo hay 3 mujeres entre los 36 miembros; en la de Ciencias Exactas, Física y Química y Naturales, tan sólo 2 entre 55, al igual que en la de Ingeniería aunque ésta cuenta con menos miembros (44 en total); y en la de Real Academia de Medicina que tiene 46 miembros, tan sólo hay una. En total, de los 654 miembros que componen las 10 Reales Academias, las mujeres sólo constituyen el $5,53 \%{ }^{11}$.

Ahora bien, ¿qué mecanismos han imposibilitado - y aún hoy imposibilitan- el acceso a las instituciones educativas y científicas a lo largo de la historia? ¿Cuáles son las causas de que las mujeres se queden en determinadas profesiones o áreas y no alcancen los puestos más elevados más que en proporciones que no se corresponden con la masa crítica existente? La historia y la sociología muestran que, por un lado, las mujeres eran - son- admitidas prácticamente como iguales hasta que una actividad se institucionaliza y profesionaliza y que el papel de las mujeres en determinada actividad es inversamente proporcional al prestigio de esa actividad. Por otro, se han apreciado dos formas fundamentales de discriminación, la territorial y la jerárquica. Por la primera, las mujeres quedan relegadas a disciplinas y trabajos concretos, marcados por el sexo, como la clasificación y catalogación en historia natural o la computación de datos en astronomía. Así a esos trabajos o carreras «feminizados» se les atribuye menor valor, se los considera rutinarios o poco importantes, por el hecho de ser realizados por mujeres. En virtud

10 Para un análisis más detallado de la situación en las instituciones académicas e investigadoras, véase, Pérez Sedeño y Alcalá Cortijo 2007, Pérez Sedeño (coord.), 2003, FECYT, 2007 y UMYC, 2007.

11 Datos del Instituto de la Mujer del Ministerio de Trabajo y Asuntos Sociales. 
de la denominada discriminación jerárquica, mujeres brillantes y capaces son mantenidas en los niveles inferiores del escalafón o topan con un «techo de cristal» que no pueden traspasar en su profesión ${ }^{12}$. Finalmente, se reconoce que las mujeres están excluidas de facto de las redes informales de comunicación, cruciales para el desarrollo de las ideas y para alcanzar posiciones relevantes. En resumen, soportan formas encubiertas de discriminación y microdiscriminaciones que pasan desapercibidas a menudo y crean un ambiente tal que muchas mujeres desfallecen y abandonan porque siguen pautas muy sutiles. Esas desigualdades se manifiestan en comportamientos que sirven para singularizar, apartar, ignorar o descalificar de cualquier modo a un individuo, en función de características inmutables y que no dependen de su voluntad, esfuerzo o mérito, como el sexo, la raza o la edad. Crean un entorno laboral y educacional que menoscaba el rendimiento de estos sujetos, porque hace falta tiempo y energía para ignorar este tipo de comportamientos y hacerles frente. Todos estos trabajos han llevado a estrategias y propuestas de acción política y social, en algunos casos incluso incorporados en los programas y actuaciones de algunos partidos políticos y gobiernos, como ha sucedido recientemente en nuestro país ${ }^{13}$.

Pero para subsanar esas deficiencias, además de adoptar estrategias y medidas sociopolíticas es importante que las niñas y las mujeres tengas espejos en los que mirarse, modelos de referencia. Ese papel se ha intentado cubrir rescatando del olvido figuras que habían pasado inadvertidas o deliberadamente ocultas en la historia de la ciencia. La recuperación de científicas dio origen a una serie de historias de las mujeres en disciplinas concretas y a biografías de mujeres que han efectuado aportaciones más o menos importantes a la ciencia y la tecnología que no aparecen recogidas en las historias al uso. Estos estudios tienen la característica de que no se limitan a coleccionar listas de nombres de mujeres científicas o tecnólogas, sino que hacen hincapié en las circunstancias familiares, sociales y económicas que hicieron posible su dedicación en un ámbito manifiestamente hostil, pues, por lo general, esas mujeres tuvieron oportunidades impensables en su época: eran de clase alta, hijas, hermanas o esposas de científicos o personas ilustradas, etc. (Pérez Sedeño, 2005).

Así, el feminismo produjo un acercamiento a la ciencia y la tecnología desde una perspectiva diferente, sin prejuicios ni preconcepciones caducas.

12 Los últimos datos de nuestro país muestran una cierta redistribución del mapa de la discriminación territorial en la Universidad, pues tan sólo las ingenierías siguen siendo refractarias a la participación de las mujeres. No obstante, la discriminación jerárquica y el techo de cristal permanecen inamovibles: sólo un $13,7 \%$ de catedráticas y 4 rectoras en 72 universidades.

13 Esto fue especialmente notorio a raíz de las medidas aprobadas en el Consejo de Ministros y publicadas en el BOE del 8 de marzo de 2005 y luego la Ley Orgánica para la Igualdad efectiva entre mujeres y hombres, publicada en el BOE del 23 de marzo de 2007. 
Ha sacado a la luz la participación de las mujeres en tradiciones que, en muchos casos por ser «femeninas» han quedado en la oscuridad o no se les ha dado importancia (como el trabajo de matronas o herboristas en medicina). También ha servido para hacer hincapié en trabajos invisibles y no reconocidos, pero fundamentales para el desarrollo de la ciencia (computar datos astronómicos, clasificar y catalogar en historia natural, labores de técnicas de laboratorio, ilustración, enseñanza...) Y ha subrayado el valioso papel de las mujeres en fenómenos fundamentales para el progreso de la ciencia y la tecnología (salones científico-literarios, mecenazgo, divulgación, edición,...) y en el nacimiento y desarrollo de determinadas áreas como la botánica, la paleontología, o la informática ${ }^{14}$.

Las preocupaciones feministas con respecto a la ciencia han producido cambios sociales y políticos, pero también han modificado el campo educativo. La perspectiva feminista ha tenido como consecuencia en la historia de la ciencia y la tecnología la de reconsiderar el propio objeto de estudio: qué se considera ciencia y tecnología y qué actividades y fenómenos hay que tener en cuenta a la hora de estudiar su desarrollo. La crítica de la invisibilidad de las mujeres como protagonistas del mundo en que vivimos no se ha quedado en la historia de la ciencia, sino que se ha extendido a otros tipos de historia y a disciplinas tales como la sociología, la arqueología o la economía, contribuyendo también a la reconfiguración del objeto de estudio de esas disciplinas.

\section{Los contenidos de la ciencia}

El hecho de que el conocimiento se haya utilizado para sojuzgar a las mujeres ha creado unos lazos muy especiales que han llevado a examinar muy detenidamente, y desde una perspectiva feminista, las teorías científicas concretas que tienen que ver con el género y las mujeres, así como los procedimientos empleados para llegar a ellas, en especial las disciplinas biosociales por el papel central que desempeñan en el mantenimiento del orden «genérico» de la sociedad ${ }^{15}$.

14 En la historia de la tecnología el camino recorrido ha sido semejante. Por un lado, se ha prestado atención al ámbito de lo privado, es decir de lo femenino, en el que se utilizaban y utilizan tecnologías propias de las tareas tradicionalmente determinadas por la división sexual del trabajo y que no han contado como desarrollos «tecnológicos». Pero también se han recuperado mujeres con aportaciones en tecnologías «típicamente masculinas».

15 Es decir, el orden social que atribuye una posición diferente a cada uno de los sexos. La sociología, impulsada por teóricas feministas, ha consagrado la distinción entre «sexo» y «género», que puede evitar interpretaciones espurias. Cuando se habla del primero, nos referimos a características «naturales», como cromosomas o genitales, aunque no es algo simple, sino que tiene distintos aspectos y en cada persona se pueden reunir unos diferentes. El género, por su parte, también tiene diversas dimensiones: la identidad, el rol, las normas, las virtudes, el comportamiento y el simbolismo de género (Anderson, 2003; Pérez Sedeño, 2006). 
Así pues, no resulta extraño que ya a finales del siglo XIX y principios del $\mathrm{XX}$, coincidiendo con el movimiento sufragista y la lucha por lograr el acceso de las mujeres a las instituciones de educación superior, surgiera un gran interés por aquellas disciplinas, hipótesis y teorías que, mediante investigaciones y experimentos pretendían probar la inferioridad intelectual de las mujeres ${ }^{16}$. Las primeras psicólogas tuvieron un papel destacado en ello ${ }^{17}$. Se examinaron y criticaron esas teorías que buscaban diferencias que hoy denominaríamos «diferencias cognitivas» (cerebrales, craneales o neurológicas), analizando los sesgos y buscando su refutación mediante estudios, ensayos o experimentos ${ }^{18}$. Resulta curioso, sin embargo, que sigamos teniendo noticias de investigaciones que hablan de la supuesta superioridad de los chicos en matemáticas, de incapacidad «innata» (esto es «genética») para la ingeniería, etcétera. Y, de vez en cuando, esas ideas provocan debates como el que se dio en la famosa y prestigiosa Universidad de Harvard, a raíz de las declaraciones de su entonces presidente, Lawrence Summers, quien manifestó en una conferencia pronunciada el 14 de enero de 2005, que si las mujeres no lograban llegar a lo más alto en matemáticas y ciencias e ingenierías se debía a una incapacidad innata en ellas ${ }^{19}$.

Para ser más precisos, según Summers tres hipótesis explicarían las «sustantivas disparidades en relación con la presencia de mujeres en profesiones científicas, en el más alto nivel». La primera de ellas sería la hipótesis del dinamismo en el trabajo, es decir, las mujeres no quieren trabajar 80 horas a la semana, algo necesario para llegar a lo más alto en la ciencia. La segunda sería la diferente aptitud o capacidad en matemáticas entre hombres y mujeres, dicho de otro modo, pequeñas diferencias de aptitud media en matemáticas o ciencias se traducen en una gran disparidad en el nivel intelectual que se necesita para hacer ciencia. Por último, la tercera hipótesis se refiere a la diferente socialización y los patrones de discriminación: a las niñas y a las mujeres jóvenes se les expulsa de la ciencia y de la ingeniería y las que entran en esos campos padecen discriminaciones mientras tratan de progresar en sus carreras. Summers aclaró que las dos primeras hipótesis eran las que realmente servían para explicar la sub-representación de las mujeres en los niveles más altos de las carreras científicas y que la última apenas tenía importancia ${ }^{20}$.

16 También, y dentro del movimiento del evolucionismo social, surge un grupo que plantea el papel de las mujeres en los orígenes de la humanidad (Arwil-Nordbladh, 1989).

17 Véase, al respecto, el estupendo trabajo de Silvia García Dauder (2005).

18 Los trabajos al respecto son muy amplios, pero véase, por ejemplo Birke (1992), Tobach y Rosoff (1994), Gómez (2004) o García Dauder (2005).

19 Dicha afirmación tuvo gran eco en la prensa. Véase, por ejemplo, http://www.boston.com/news/local/articles/2005/01/17/summers_remarks_on_women_draw_fire/?page=1, http://topics.nytimes.com/top/reference/timestopics/people/s/lawrence_ $\bar{h} \_$summers/index.html?inline $=$ nyt-per.

20 Hay que señalar que el 17 de febrero, Summers declaró: «las observaciones que hice en enero subestimaron de manera importante el impacto de la socialización y la discriminación, 
Como ya he mencionado, las declaraciones del entonces presidente de Harvard provocaron una gran polémica entre defensores y detractores de la eufemísticamente denominada «diferencia» en aptitud matemática entre hombres y mujeres. Pero, en realidad, se habla de capacidad inferior de las mujeres para las matemáticas, pues si las diferencias no supusieran o conllevaran afirmaciones de inferioridad, no se producirían tales controversias.

Cuando se habla de diferencias cognitivas y conductuales entre los sexos, por lo general se recurre a la supuesta evidencia que hay a favor de la existencia de diferencias entre hombres y mujeres en la capacidad innata para las matemáticas. En nuestra cultura (científica) hay mucho respeto por la capacidad matemática, por lo que esa afirmación tiene mucho peso y puede hacer mucho daño. Así que debemos plantearnos tres cuestiones. La primera es de qué hablamos, es decir cuáles son exactamente las diferencias entre hombres y mujeres cuando hacen pruebas matemáticas (y de qué pruebas hablamos). En segundo, qué tipo de evidencia sugiere o está en contra de la idea de que esas diferencias son innatas (es decir que se nace con ellas y son inmutables). $\mathrm{Y}$ en tercer lugar por qué debe importarnos los resultados de esas pruebas matemáticas, es decir si predicen realmente el éxito en ciencia e ingeniería, que es lo que parece estar implícito en la afirmación de Summers y otros defensores de estas ideas. Porque el argumento que subyace a la afirmación de Summers y otra gente es el siguiente: dado que las mujeres son innatamente inferiores en capacidad matemática, no importa la educación que se les dé, ni las políticas educativas o de acción compensatoria (las mal llamadas «discriminaciones positivas») que se sigan, las mujeres nunca llegarán a lo más alto en las carreras científico-tecnológicas.

Es importante cuestionarse por qué hay que explicar de manera biológica las diferencias en capacidades o habilidades cognitivas, cuando parece igualmente plausible una explicación sociológica, dadas las diferencias educativas entre chicos y chicas. Pero las investigaciones realizadas en ese sentido son pocas, aunque tenemos resultados que demuestran que, tras políticas educativas de igualdad, los resultados obtenidos por los chicos y chicas pueden equipararse ${ }^{21}$. Sin embargo, los científicos parecen guiarse por el supuesto de que las diferencias entre hombres y mujeres son «naturales».

incluyendo las actitudes implícitas, esto es, patrones de pensamiento a los que estamos sujetos todos de manera inconsciente. La cuestión de las diferencias de género es mucho más compleja de lo que se entreve en mis comentarios y mis observaciones sobre la variabilidad fueron mucho más lejos de lo que la investigación ha establecido». Letter to the Faculty Regarding NBER Remarks, en http://www.president.harvard.edu/speeches/2005/facletter.html. No obstante, eso no le evitó una moción de censura y un voto de no confianza de la prestigiosa Facultad de Ciencias y Artes, algo que sucedía por primera vez desde la fundación de Harvard en 1636, y que concluyó con su dimisión el 21 de febrero de 2006.

21 Los resultados arrojados por los distintos informes PISA así parecen demostrarlo (Pérez Sedeño, 2006) 
En las últimas décadas ha habido un renovado interés por medir partes del cerebro para ver si hay diferencias sexuales. Una vez «encontradas», como sucedía con los estudios del siglo XIX, estas diferencias parecen proporcionar evidencia en favor de una base biológica de un montón de diferencias sexuales en la conducta. Este renovado interés surgió en los años 60 y 70 y sigue provocando gran inquietud, por ejemplo con los estudios sobre lateralización cerebral. Lo interesante es que su surgimiento coincidió con la atención que se ponía en probar diferencias sexuales y de raza en el coeficiente intelectual. Forma parte del mismo resurgir del determinismo biológico, pero se le ha prestado menos atención y no ha sido tan criticado. Eso puede deberse a que las nuevas mediciones del tamaño cerebral y de la estructura del cerebro apuntan a diferencias sexuales, no ha diferencias entre negros y blancos y a que hoy en día la gente tolera más el sexismo que el racismo ${ }^{22}$. Pero también puede deberse a que la mayor parte de los investigadores han generado sus datos aplicando nuevas tecnologías al estudio de cerebros animales, fundamentalmente ratas, en vez de a cerebros humanos. En el año 1991 se publicó un estudio ${ }^{23}$ en el que se midió el tamaño y la proporción de desarrollo del hipocampo en aborígenes australianos y caucasianos. En el estudio se señalaba que en las mujeres aborígenes se daba el menor crecimiento de esta parte del cerebro y los autores formulaban la hipótesis de si era debido a diferencias genéticas — por implicación vinculadas al sexo- a la dieta pobre o ambas cosas.

Pero éste es sólo un ejemplo de los análisis que se hacen de diversas teorías, hipótesis o áreas científicas desde el feminismo.

La sociobiología constituye un ejemplo paradigmático de cómo se puede utilizar la ciencia para justificar la situación social y legal ${ }^{24}$. Podemos decir que aparece en 1975, con la publicación del libro de E. O. Wilson, Sociobiology: A new Synthesis. Profundamente determinista, afirma la existencia de genes para la agresividad, la territorialidad y la inteligencia, características del estereotipo masculino de las sociedades occidentales, por lo que la sociobiología refuerza la «naturalidad» de la dominación masculina, a la vez que «explica», y condena, la violencia existente en la sociedad. La sociobiología aparentemente proporciona una justificación científica para el orden social existente y ofrece una explicación genética, por tanto fija e inmutable, de las diferencias sociales, justificando el dominio de un grupo por el otro.

Según esta teoría, hay rasgos universales que identifican a los humanos, sin que importen diferencias culturales o históricas. La universalidad de esos

22 Por ejemplo, se toleran mejor los chistes machistas que los racistas.

23 Citado y comentado en Tobach y Rosoff (1994).

24 Kingsley Browne (1998) afirmaba en los «Darwin Seminar» de la London School of Economics que las diferencias de salario y jerarquía que se dan entre hombres y mujeres en el trabajo no pueden atribuirse a la pura discriminación, sino a las diferencias con que han evolucionado los dos sexos. 
rasgos es evidencia de que son adaptativos, esto es, sucesivas generaciones los heredan y quienes los tienen, dejan más descendencia. El término «adaptativo» tiene un significado especial en este contexto. Lo que quiere decir es que sucesivas generaciones heredan sin cambiar esos rasgos y que los individuos que los exhiben tienen más descendientes que los que no los exhiben. Así, los genes de rasgos más adaptativos sobrepasan el número de los rasgos menos adaptativos hasta que los más adaptativos se convierten en universales. Los sociobiólogos mantienen que tratamos de hacer las cosas que nos ayudan a extender nuestros genes y las conductas que nos permiten hacer eso de manera más eficaz se convierten en universales. Ejemplo de esas conductas son la promiscuidad masculina porque permite a los varones «diseminar su semilla» o fecundizar a tantas mujeres como sea posible; y en el caso de las mujeres o las hembras la fidelidad les permite unirse a un macho que las cuide tanto a ellas como a su descendencia.

Los sociobiólogos observan que, si hay desproporción en la contribución de hombres y mujeres en el cuidado de los niños y el hogar, es porque está biológicamente determinado o programado, pues las mujeres efectúan una «inversión» biológica mayor en los niños que los hombres. Como la adecuación biológica de un organismo, depende de que produzca el mayor número posible de descendencia que sobreviva lo suficiente como para reproducirse, el número de descendencia que se reproduce determinará la frecuencia con la que los genes de un individuo estarán representados en las sucesivas generaciones. Por ese motivo, junto a la mayor inversión biológica de las mujeres, los sociobiólogos mantienen que hombres y mujeres deben adoptar, necesariamente, estrategias básicamente diferentes para maximizar las oportunidades de extender sus genes a las futuras generaciones.

Desde luego, todo ello plantea bastantes problemas. Por ejemplo, se ignora que las sociedades humanas no funcionan con unos pocos «sementales» y que, por lo general, los hombres más poderosos y fuertes no tienen más hijos. Por otro lado, ¿a qué se refieren con la «mayor inversión biológica» de la madre en la reproducción? Puestos a contar, contemos lo que invierten biológicamente una mujer y un hombre respectivamente, en la reproducción. Supongamos que una mujer «libere» 500 óvulos a lo largo de su vida reproductiva y que tenga 2-3 hijos. Eso supondría una inversión de unos 250-170 óvulos por hijo. Ahora bien, supongamos el mismo número de hijos en la vida reproductiva de un varón. Si produce 200.000.000 de espermatozoides diarios, a lo largo de 40 años (supongamos que está activo hasta los 55 años, aunque sabemos que, aunque la producción de espermatozoides disminuye con la edad, no desaparece), habrá producido 73.000.000.000 de espermatozoides al año, unos 2.920.000.000.000 en toda su vida. Es decir, habrá utilizado entre 1.460.000.000.000 y 973.000.000.000 espermatozoides por hijo. ¡Eso es inversión biológica!

Por lo que se refiere a la supuesta promiscuidad de los machos-varones y la supuesta fidelidad de las hembras-mujeres, podrían no ser tan ventajosas, 
al menos para éstas: si una mujer es promiscua puede tener a varios hombres cuidando a su descendencia en vez de a uno solo.

Resumiendo las múltiples críticas que se les han realizado a los sociobiólogos, agrupan bajo el mismo nombre, conductas muy diferentes, humanas y no humanas y emplean argumentos circulares: parten del comportamiento social de determinadas especies para explicar precisamente dicho comportamiento, a la par que se utilizan el lenguaje y los marcos conceptuales humanos para interpretar el comportamiento animal que luego se utiliza para «probar» que cierta conducta humana está biológicamente determinada porque los animales la tienen. Además, eliminan contextos y significados culturales, obvian la gran variedad de conducta animal existente y establecen analogías y homologías sin fundamentar, pues no está clara la pertinencia de extrapolar de unas especies a otras, en concreto a la humana, dada la complejidad de nuestra especie, conformada durante siglos por factores socioculturales además de biológicos.

Por lo general, las críticas vertidas sobre esta y otras teorías o disciplinas sacan a la luz la utilización de argumentos falaces, la existencia de fallos en el diseño experimental y de supuestos basados en datos experimentales limitados, extrapolaciones insostenibles, manipulaciones tecnológicas, dudosa universalidad de ciertos «hechos» y la obtención de resultados contradictorios con respecto a ellos, etc. Y además de las deficiencias metodológicas indicadas, se critica el paso de los supuestos hechos probados a tesis sobre el puesto de las mujeres en la sociedad que pretenden perpetuar el estatus de dominación y subordinación de las mujeres. Resumiendo, todas las críticas coinciden en señalar cómo histórica y actualmente se pretende inferir de supuestas observaciones de «hechos biológicos» (ya sean craneales, cerebrales, hormonales, etc.) diferencias intelectuales y sociopolíticas. En general han subrayado que los argumentos biológicamente deterministas conducen a políticas conservadoras justificadoras del orden social existente y que, en casos extremos, puede llevar a intervenciones biológico-médicas, cuyo control escapa, en la mayoría de las ocasiones, a sus usuarios/as.

\section{Filosofía de la ciencia desde el feminismo}

La reflexión feminista sobre la ciencia no es, ni mucho menos, única y se nutre de críticas como las ya señaladas, las lecturas feministas de la historia de la filosofía, la investigación sobre psicología educativa y los análisis de los supuestos y presuposiciones de la epistemología analítica. Normalmente se distinguen cuatro enfoques: el psicodinámico, que cuestiona la separación objeto/sujeto (Evelyn Fox Keller), el del «punto de vista», que aboga por una multiplicidad de perspectivas en las que el género será una de entre otras variables (Sandra Harding), el postmodernismo, que señala la necesidad de una 
nueva ontología en un mundo en el que se han difuminado los límites ontológicos tradicionales entre lo orgánico y lo mecánico, entre lo innato y lo medioambiental (Donna Haraway) y el empirismo, bien en su versión más ingenua o en la más sofisticada (Helen Longino), que es la que adoptaremos en lo que sigue.

La filosofía de la ciencia - fundamentalmente filosofía de la física- se desarrolló, desde comienzos del siglo XX intentando transformar los conceptos y teorías científicas en objetos apropiados para estudios metateóricos exactos. Esta pretensión aspiraba a abarcar no sólo a las ciencias empíricas, sino también a la filosofía. La filosofía de la ciencia, heredera del Círculo de Viena y del empirismo lógico, se desarrolló después de la Segunda Guerra Mundial de la mano de autores como Carl G. Hempel o Ernest Nagel y hoy se conoce como la concepción heredada o la leyenda ${ }^{25}$. Se basaba en una serie de distinciones y supuestos fundamentales, que, además, servían para delimitar las tareas de la filosofía de la ciencia frente a otras disciplinas como la historia, la sociología o la psicología de la ciencia, a saber, la distinción entre «hechos» y «valores». Esta distinción es dicotómica, excluyente y jerárquica, dado que, para los filósofos de la ciencia, el lado de la dicotomía de los «hechos» era claramente superior (por racional y objetivo) al de los valores. La ciencia trata de hechos y las teorías son conjuntos de enunciados acerca de los hechos que, por tanto, pueden ser verdaderas o falsas ${ }^{26}$. Los valores son ideas acerca de lo que es deseable y se expresan en normas o criterios que indican cómo actuar en situaciones concretas. La verdad o falsedad son propiedades que no se pueden atribuir ni a los valores (que serán buenos, adecuados, etc., pero nunca verdaderos o falsos) ni a los enunciados normativos, evaluativos o deónticos que adscriben a un agente la obligación de actuar, o atribuyen la cualidad de bueno a algo. La reflexión de segundo orden que es la filosofía de la ciencia, sólo se ocuparía de los enunciados acerca de «lo que es», quedando los juicios de valor, sobre «lo que debe ser», relegados a otro dominio.

25 Hay otras escuelas, como la denominada «continental» en la que se incluyen la escuela de Frankfurt o el post-estructuralismo francés. No obstante, la dominante durante el siglo XX en los países de habla inglesa y en el nuestro, ha sido ésta.

26 Por supuesto, esto es una simplificación, pero en lo fundamental es ajustado y sirve como fundamento de las características que esta concepción atribuye a la ciencia. De hecho, muchas de las críticas iniciales versan sobre esta idea de que la ciencia está constituida por leyes y teorías que tratan sobre hechos. T. S. Kuhn, S. Toulmin, N. R. Hanson o P. K. Feyerabend, consideraban una limitación de la filosofía de la ciencia que sólo se dedicara a la parte estática de la ciencia. También fue objeto de crítica la distinción «clara» entre lenguaje teórico y observacional, intentándose explicar aquél en términos de éste, el único comprensible y fiable, fundamental para la justificación de las hipótesis o teorías. Como bien señalara Hanson, la evidencia empírica no basta para determinar la verdad o falsedad de una hipótesis (excepto en casos triviales), pues no hay un observador neutral, alguien que no observe «con los ojos de una teoría». Esta constatación conduce a la infradeterminación de las teorías científicas, de la que hablaremos más adelante. Por otro lado, hay concepciones, como la estructuralista, que consideran — que las teorías son entidades modelo-teóricas, esto es, conjuntos de modelos. 
Un aspecto importante de esta concepción de la ciencia es la distinción entre la producción del conocimiento y su justificación. El primer proceso, conocido como contexto de descubrimiento, tiene que ver con los diversos factores que influyen en los científicos cuando formulan las hipótesis científicas que hay que contrastar; al segundo, el contexto de justificación, sólo le importa o le interesa la confirmación o refutación de las hipótesis científicas. La concepción tradicional de la ciencia, y por tanto la filosofía de la ciencia dominante durante gran parte del siglo XX, se centró en el contexto de justificación, considerando que ese proceso es lo que distingue a la ciencia de cualquier otra actividad y genera la objetividad característica del conocimiento científico. Sólo el contexto de justificación es relevante para la epistemología de la ciencia, mientras que el contexto de descubrimiento es el objeto de otras disciplinas. Mientras que no hay métodos para la formulación de hipótesis pues es una actividad creativa, sí que lo hay en la confirmación y eso lo que le da la ciencia la marca o el marchamo de conocimiento.

El método sería aproximadamente el siguiente. Una vez que se formula una hipótesis $(\mathrm{H})$, hay que someterla a prueba, esto es, ideando una experiencia contrastadora que permita averiguar si nuestra $\mathrm{H}$ es verdadera o falsa. Para ello, se deduce una predicción (P) de esa $\mathrm{H}$, con la ayuda de las condiciones iniciales $(\mathrm{CI})$ de la experiencia contrastadora, más los supuestos auxiliares necesarios para poder derivar P. Una vez ejecutamos el experimento o experiencia, si se cumple lo predicho por $\mathrm{P}$, podremos pasar a justificar la verdad de nuestra $\mathrm{H}$ y si no, su falsedad ${ }^{27}$. Por supuesto, esta descripción es muy esquemática, pero sirve para mostrar que en el contexto de justificación, el único del que se ocupa la filosofía de la ciencia, sólo tienen cabida consideraciones lógico-empíricas.

Así pues, la concepción heredada mantiene que la creatividad es fundamental en la formulación de hipótesis, pero su relevancia para la reflexión filosófica sobre la ciencia, en concreto para la justificación de nuestras creencias científicas (que es de lo que se debe ocupar la filosofía de la ciencia) es nula. El método de contrastación mediante la lógica más la evidencia empírica elimina de la ciencia cualquier influjo subjetivo que pudiera haber entrado en ella a través del contexto de descubrimiento. Así se excluyen los valores de la ciencia y la convierten en "valorativamente neutra».

La neutralidad de la ciencia significa que las teorías no implican ni presuponen juicios sobre valores no cognitivos y que las hipótesis o teorías científicas no sirven a unos valores no cognitivos concretos más que a otros. Pero la neutralidad valorativa no es la única característica que esta concepción atribuye a la ciencia, pues se considera que, además, es autónoma e imparcial. La

27 La justificación de la verdad de $\mathrm{H}$ exige un argumento inductivo en el que las premisas deben ser verdaderas, y la justificación de la falsedad de $\mathrm{H}$, un argumento deductivo con premisas asimismo verdaderas. Esto también plante problemas, pero no vienen al caso ahora. 
autonomía de la ciencia denota que la ciencia progresa mejor cuando no está influida por valores o movimientos sociales o políticos. Y la imparcialidad supone que la única base para aceptar una teoría son sus relaciones con la evidencia y no valores no cognitivos.

De estas tres afirmaciones la condición más dura es la neutralidad porque conlleva que la base para aceptar los valores morales, políticos o sociales está separada profundamente de la evidencia que tenemos sobre las potencialidades humanas y sobre lo que sucede cuando la gente intenta poner en práctica estos valores. La neutralidad es menos una afirmación sobre el carácter de la ciencia que sobre la justificación de los valores políticos y sociales. Y con respecto a esto último, Taylor (1985) y Tiles y Oberdiek (1995) han mostrado con estudios de casos detallados, cómo una serie de teorías científicas sirven mejor a unos valores políticos y sociales que a otros.

La afirmación central sobre la neutralidad valorativa, es, no obstante, la imparcialidad, pues detrás de ella está la idea de que las teorías científicas pretenden conseguir la verdad, es decir lo que es el caso, mientras que los juicios de valor se ocupan de lo que debe ser el caso. Aunque la neutralidad sea falsa, porque los hechos constituyen parte de lo que garantiza los juicios de valor, lo inverso no es cierto. Los hechos sólo pueden proporcionar garantías para los hechos. La autonomía, a la vez, se considera como un medio para asegurar que la ciencia satisface las exigencias de imparcialidad. Los defensores de la imparcialidad están en contra de la idea misma de «ciencia feminista» ${ }^{28}$ porque consideran que amenaza la imparcialidad. Se considera que lo político y social amenaza la autonomía porque su influjo primario en la ciencia consiste en hacer presión en los científicos para que ignoren los hechos y validen sus concepciones del mundo.

En una ciencia así, no tendrían cabida consideraciones éticas, políticas, sociales, etc. Entonces, ¿qué hacer con el feminismo, que pretende introducir sus valores en la ciencia? De hecho, una de las acusaciones más duras que se le hace a la filosofía feminista de la ciencia es que pretende ser políticamente correctas, es decir, que quiere dar criterios políticos para anular o restar valor al razonamiento científico basado en la evidencia, para suprimir verdades incómodas o inconvenientes para la agenda feminista y promulgar falsedades que coincidan con ella ${ }^{29}$. Pero son muchos los casos en que las consideraciones feministas han servido para mejorar la ciencia, para hacerla de verdad universal.

Cuando se afirma que la «ciencia está libre de valores» no se está haciendo una afirmación en términos absolutos, pues la ciencia tiene los valores que

${ }^{28}$ Ha habido muchas objeciones a la idea misma de «ciencia feminista» al igual que a «epistemología feminista» o «filosofía feminista de la ciencia». Aunque no es el momento aquí para hacer un estudio de la polémica suscitada, debo decir que, aunque usaré a veces esa expresión, ha de entenderse simplemente como la ciencia que se hace desde una perspectiva feminista o que utiliza el feminismo como teoría crítica para enfrentarse a problemas epistemológicos o filosóficos.

29 Por ejemplo Pinnick, Koertge y Almeder, 2003. 
generan los fines de la investigación científica y según qué consideremos la finalidad de la ciencia tendremos unos u otros valores en funcionamiento. Es cierto que uno de los fines de la actividad científica es la obtención de conocimiento, pero, además, la práctica científica es efectuada por individuos que colaboran entre sí, de una manera socialmente organizada y que se desarrolla en contextos sociales, políticos e históricos concretos con los que interactúa. La afirmación que se está realizando cuando se habla de una ciencia libre de valores se refiere a los valores contextuales o no constitutivos. Así, se distingue entre valores constitutivos (o internos o epistémicos) y valores no-constitutivos (o externos o contextuales). Los primeros serían los que están en la base de las normas o reglas metodológicas que determinan qué constituye una práctica científica, o metacientífica aceptable (contexto de justificación), mientras que los segundos pertenecerían al ámbito cultural y social en que se desarrolla la actividad científica (contexto de descubrimiento).

La afirmación de que la ciencia está libre de valores significa que los valores constitutivos y contextuales constituyen conjuntos disjuntos e independientes entre sí y, además, hace referencia a la autonomía y a la integridad de la investigación científica. La tesis del carácter autónomo de la ciencia mantiene que no se ve afectada por los valores e intereses del contexto sociocultural. Puede que en ciertos momentos esos valores ejerzan algún influjo, diría la concepción heredada, de modo que, por ejemplo surge la prueba definitiva, esa idea tan buscada, etc. Pero ese influjo no afectará el núcleo central de la ciencia. Dicho una vez más, en la práctica interna de la ciencia - en la observación, experimentación, inferencias y contrastación de teorías - no tienen cabida los valores contextuales, sólo los cognitivos o internos.

Según esta neutralidad con respecto a los valores, sólo cuando se eliminan los valores se logra la objetividad propia del conocimiento científico. Muchos de los casos estudiados por el feminismo, como algunos de los mencionados en este artículo, son compatibles con esta interpretación, pues se puede considerar que el hecho de que los valores influyan produce malos resultados, esto es, las teorías antes mencionadas no estarían justificadas. Incluso la concepción tradicional del método científico puede acomodar la afirmación de que los valores feministas tienen un influjo positivo en la investigación científica, pero este influjo quedaría restringido al contexto de descubrimiento. Los valores serían instrumentales en la formulación de hipótesis buenas pero no formarían parte de la evidencia a favor de ellas, como en el caso de la Hipótesis de la Mujer Recolectora en el que los principios feministas obraron para idearla como hipótesis alternativa a la del Hombre Cazador ${ }^{30}$. También podrían ayudar a diseñar experimentos para contrastar hipótesis científicas (por ejemplo, los valores feministas de una científica podría alertar acerca de algunos aspectos no contemplados en un

30 Pérez Sedeño, 2005. 
experimento), pero nunca intervendrían en la justificación posterior a la experimentación.

Ahora bien, desde algunos sectores feministas se ha realizado una interpretación diferente sobre el papel de los valores en las diversas dimensiones de la ciencia, según la cual ya no supondrían una intrusión, sino que formarían parte constitutiva de la ciencia. Es decir, se mantiene que los valores no sólo intervienen en el contexto de descubrimiento sino también en el de justificación y que, además, no siempre que los valores intervienen lo que tenemos es mala ciencia en el sentido de mala aplicación del método científico. Esto es importante porque normalmente se suelen poner ejemplos en los que las teorías científicas tratadas o analizadas son rechazadas finalmente; pero ese hecho sólo no justifica la afirmación de que constituyan casos de mala ciencia. De hecho, si consideramos la historia de la ciencia, la mayor parte de las teorías científicas acaban siendo suplantadas por otras. Si caracterizáramos todas las teorías pasadas rechazadas como ejemplos de mala ciencia, tendríamos que mantener que la ciencia por, lo general, se hace mal.

Considerar que la ciencia por lo general se hace mal nos lleva a dos cuestiones separadas. A menudo la mala ciencia se contrapone a «la ciencia como se hace usualmente», sugiriendo que las teorías malas son el resultado de prácticas científicas no habituales. Pero la investigación científica plagada de valores, incluyendo valores sexistas, no es inusual y la buena ciencia, la que se realiza normalmente, no es de un tipo distinto. Parte del trabajo realizado, por ejemplo, en la biología de las diferencias sexuales no podría ser clasificado de este modo, pues forma parte de la ciencia normal ${ }^{31}$.

Las feministas han proporcionado varios argumentos para afirmar la inadecuación de las concepciones de la ciencia que suscriben el mito de su neutralidad valorativa y de que, a diferencia de cualquier otra actividad humana, se puede entender fuera de su contexto social y cultural. Por un lado, eso conduce a la complacencia, pues evita examinar la posibilidad de que el «conocimiento» establecido pueda servir los intereses de grupos dominantes de la sociedad (y fomentaría la injusticia), a la vez que anima a despreciar los análisis feministas del influjo de los supuestos de género en casos de buena ciencia o de ciencia con éxito ${ }^{32}$.

Desde la concepción heredada ${ }^{33}$ se mantiene que aceptar que los valores intervienen en la ciencia equivale a legitimar la idea de que «los valores feministas deben determinar qué teorías se aceptan», lo que amenaza la «investigación honesta» que es la «investigación no informada por ninguna idea política» ${ }^{34}$. La filosofía feminista de la ciencia pretendería «constreñir ideo-

31 Longino 1990.

32 Tanessini, 1999.

33 Véase Pinnick, Koertge y Almeder (eds.) (2003) que constituye un buen ejemplo de las críticas a la filosofía feminista de la ciencia, especialmente a Helen Longino.

34 Haack, 2003, pp. 12-16. 
lógicamente el contenido de la ciencia», instaurar el dogmatismo «eliminando la discusión abierta», reemplazando los «cánones tradicionales de evidencia y argumentación» por la política de los oprimidos ${ }^{35}$. Desde luego estas acusaciones son muy graves, pues no sólo acusa a la epistemología feminista de estar equivocada, sino de deshonestidad intelectual, de dogmatismo e incluso de tiranía.

El empirismo contextual considera que los argumentos que hacemos a favor de ciertas evidencias dependen del contexto y que consideramos que ciertos datos constituyen evidencia a favor o en contra de ciertas hipótesis sólo con respecto a ciertas hipótesis o supuestos previos o de trasfondo. En la práctica, en la vanguardia de la investigación hay supuestos de trasfondo que son incompatibles a la hora de interpretar la evidencia. Como se pueden seleccionar de forma legítima diversos supuestos de transfondo, no hay principios metodológicos ni lógicos que eviten que los científicos elijan algunos que estén en consonancia con sus valores políticos o morales. Longino concluye que las feministas pueden seleccionar sus supuestos de trasfondo de modo que estén en consonancia o sean congruentes con los valores feministas. Eso es lo que quiere decir Longino cuando afirma que el científico o científica feminista «admite consideraciones políticas como constricciones es relevantes al razonamiento» ${ }^{36}$. Es decir, la construcción del conocimiento es una práctica social; por eso, la investigación conlleva valores e ideología, pero eso no supone que haya que tolerar de forma indiscriminada las preferencias subjetivas individuales. Lo que confiere objetividad a los productos de la investigación científica es la crítica social más la evidencia empírica. Dicho de otro modo, se entiende que el conocimiento científico es, sobre todo, una práctica que tiene lugar en un contexto particular y es evaluado con respecto a fines particulares: la ciencia es un proceso y actividad de comunidades científicas insertas en contextos sociohistóricos concretos en cuyo seno encontramos valores personales, sociales y culturales, preferencias de grupos o individuales, de tipo cultural, social, que inciden o pueden incidir en diversos modos y grados sobre la práctica científica.

La infradeterminación de las teorías científicas mantiene que, dada cualquier teoría o hipótesis, siempre se pueden formular un cierto número de teorías o hipótesis alternativas que sean empíricamente equivalentes a la primera, aunque las explicaciones causales del fenómeno en cuestión propuestas sean incompatibles. Así, cualquier cuerpo de observaciones se considera una evidencia para hipótesis concretas sólo en conjunción con ciertos supuestos de trasfondo. Si se varían estos supuestos de trasfondo las mismas observaciones apoyarán hipótesis bastante diferentes. Por ejemplo los geocentristas consideraban, en el s. XVII, que el que no se observara la paralaje estelar era

35 Pinnick et al., pp. 190 y 230.

36 Longino, 1990, p. 193. 
evidencia de la inmovilidad de la tierra, mientras que los heliocentristas consideraban que era evidencia de que las estrellas estaban muy lejos. En la práctica, los científicos enfrentan algunas constricciones a la hora de seleccionar los supuestos de trasfondo, basadas en valores cognitivos tales como la simplicidad y el conservadurismo, es decir la resistencia a revisar de una manera profunda supuestos muy atrincherados de los que dependen otras muchas creencias, pero no hay ningún principio lógico que impida a los científicos elegir diferentes supuestos de trasfondo contra los que interpretar sus propias observaciones. Además, estos valores cognitivos raras veces reducen el alcance de la elección a una sola opción y su interpretación y peso puede variar en cualquier caso (el geocentrismo fue derrotado por el conservadurismo predominante). Las empiristas feministas concluyen que, dado el alcance de la elección de los supuestos de trasfondo, no es imposible que los científicos seleccionen sus supuestos de trasfondo del modo que encaje con sus valores políticos y sociales o cualesquiera otras preferencias o intereses. De ahí se sigue que las científicas feministas pueden seleccionar sus supuestos de trasfondo del modo que encaje con sus valores feministas.

Este tipo de filosofía feminista de la ciencia considera, pues, que los valores contextuales, en concreto ideológico-políticos son constricciones relevantes en el razonamiento y la interpretación que conforman el contenido del conocimiento. Para filósofas de la concepción heredada ${ }^{37}$ eso plantea algunas posibilidades preocupantes. En primer lugar, se podría aceptar una hipótesis, aún cuando la evidencia sugiriera que es falsa, si creer en ella sirviera algún interés político y a la inversa con respecto a su rechazo. Incluso en aras de la corrección política, se podría aceptar una «hipótesis sin base empírica» por ser «políticamente progresista» ${ }^{38}$. Además, se podrían imponer constricciones políticas a la investigación de hipótesis aceptables, minando la libertad individual y de la comunidad científica, evitando que algunos científicos descubrieran ciertas verdades (ibidem). Se podrían producir debates sobre qué valores políticos deben constreñir las hipótesis aceptables. Y la autoridad de la ciencia quedaría muy mermada si la gente viera que los científicos llegaban a sus conclusiones basándose en consideraciones políticas y no en la evidencia (ibidem). Finalmente, en aquellos casos en que la evidencia no bastara para decidir entre hipótesis rivales, el argumento de Longino nos llevaría a «elegir creer en cualquier teoría que encajara mejor con nuestros propósitos políticos», cuando lo adecuado y correcto en este caso sería suspender el juicio.

Ahora bien, esos temores son infundados. En primer lugar, Longino es empirista y aunque mantiene que hay valores diferentes y que los distintos científicos pueden hacer hincapié en unos o en otros (como mantenía el pro-

\footnotetext{
37 Por ejemplo, Haack (2003) y Koertge (2003).

38 Koertge, 2003, p. 230-231.
} 
pio Kuhn ${ }^{39}$ ), hay una norma o valor que es obligatoria para todos los científicos, a saber, la adecuación empírica, es decir «la verdad de la parte observacionalmente determinable de la teorías o modelos» ${ }^{40}$. las conclusiones a las que llega una comunidad científica o epistémica son objetivas o se consideran conocimiento, en la medida en que son el resultado de la crítica intersubjetiva que «asegura que lo que se ratifica como conocimiento ha sobrevivido a la crítica desde múltiples puntos de vista», transformando de este modo «lo subjetivo en objetivo, no haciendo prevalecer una subjetividad sobre las otras» (ibidem, p. 129). Para asegurar la crítica intersubjetiva o la efectividad de las interacciones críticas, la comunidad epistémica debe establecer foros públicos para la crítica, cambiar sus creencias y teorías como respuesta a ésta, según normas públicas compartidas, y reconocer una cierta igualdad en la autoridad intelectual de los investigadores, que permita considerar que se tiene (o no) en cuenta sus opiniones por sus virtudes (o vicios) cognitivos, no por su poder o posición social.

Así pues, podemos descartar los temores de Haack, Pinnick o Koertge sobre las implicaciones del argumento de Longino. Puesto que unas y otras exigen que las teorías sean empíricamente adecuadas, como valor fundamental y primordial, queda descartado que una comunidad puede aceptar, por razones políticas, hipótesis no avaladas empíricamente. Se podrían contraargumentar que las «directrices o razones políticas» podrían impedir que se recogiera la evidencia en contra, o que se desarrollaran hipótesis mejores. Pero los requisitos para la objetividad, la intersubjetividad, elimina ese problema. Las comunidades epistémicas deben estar abiertas a la crítica y como todos poseen cierta autoridad intelectual, nadie puede obligar a los demás a elegir una teoría. Como dice Longino, los individuos tienen autonomía de opinión y es necesario que haya diversidad de perspectivas para que exista de «un discurso vigoroso y epistémicamente crítico de verdad» ${ }^{41}$. Ni siquiera el subconjunto de investigadoras que hacen ciencia desde el feminismo tienen una articulación determinada de valores feministas que domina sobre el resto, ya que, como hemos mencionado, hay diferentes perspectivas feministas. Lo que elimina la última objeción, a saber, que el progreso de la ciencia se vería dificultado por la preocupación sobre cuáles son los valores políticamente correctos: si nadie tiene la autoridad para que los otros adopten sus valores, cada uno es libre en elegir los supuestos de trasfondo según sus propios valores personales, siempre que someta a prueba sus hipótesis.

Tampoco hay por qué preocuparse por la idea de que la autoridad epistémica de la ciencia se vea minorada si la gente se da cuenta de que, en la elección de teorías, influyen consideraciones políticas, ya que todas teorías deben

\footnotetext{
39 Pérez Sedeño, 2005a.

40 Longino, 2001, pp. 185-6, 1994, p. 476.

41 Longino, 2001, pp. 131, 154.
} 
a satisfacer la prueba de la adecuación empírica. El peligro sólo se correría en el caso en que dos programas de investigación rivales pudieran afirmar que tienen éxito empírico y en que ninguno de los dos fuera refutado por la evidencia. En ese caso, la comunidad científica no podría consolidar uno sobre el otro, si es que «ambos marcos ofrecen el explicaciones coherentes y comprensivas de los datos relevantes, ninguna puede reemplazar o tomar el lugar de la otra». En ese caso, los científicos individualmente seguirán investigando en una teoría que elegirán según sea más menos congruente con sus fines políticos ${ }^{42}$. Aunque esto pueda parecer peligroso, no lo es, pues ninguna teoría concreta se podrá incorporar como conocimiento autorizado, excluyendo a sus rivales, hasta que sobreviva a la crítica desde todos los puntos de vista, incluyendo aquellos que se basan en perspectivas políticas opuestas.

Así pues, cuando Longino admite que las consideraciones políticas son constricciones relevantes sobre el razonamiento no está restringiendo el espacio de valores políticos al contexto de justificación. Lo que autoras como Longino dice en cuando afirman que podemos elegir los puestos de trasfondo y por tanto las teorías a la luz de nuestro valores es que, antes que comenzar a recoger evidencia, los científicos hacen numerosas elecciones críticas: sobre la parte de la naturaleza que investigarán, las cuestiones que quieren responder, en qué términos describirán esa parte de la naturaleza, los instrumentos de medición, procedimientos de obtención de datos, etc., y toman esas decisiones, a la luz de fines, algunos de cuales pueden ser políticos. Esas elecciones constreñirán por adelantado las hipótesis que se pueden investigar, por lo que son precondiciones inevitables de la investigación. Otros científicos pueden hacer otras elecciones y estar sujetos, por tanto a constricciones diferentes.

En este sentido, Helen Longino ha propuesto una serie de virtudes epistemológicas, valores o criterios normativos para la práctica científica. La adecuación empírica, aunque es un valor cognitivo por su capacidad para guiar la investigación, debe servir también para revelar la aparición del género en los fenómenos y los sesgos de género - racistas o de otro tipo- en la explicación que se da de dichos fenómenos, por lo que adquiriría además la consideración de contextual. La virtud (o el criterio) de la novedad recomienda las teorías y modelos que se apartan de las teorías aceptadas. La mutualidad de interacción descarta los modelos de un solo factor causal en favor de modelos dinámicamente interactivos (todos los factores influyen en los demás y no hay uno sólo dominante) lo que permite dar cuenta de fenómenos tecnocientíficos más complejos, como recientes trabajos en bioquímica celular y neurociencia muestran. Las ventajas de la difusión de poder, de sobra conocidas y postuladas desde diversos ámbitos, no sólo el feminista, permiten dar preferencia a programas de investigación que incorporan relaciones mutuas, no de

42 Ibidem, p. 130. 
dominador/subordinado y, por tanto, propicia el control democrático de la investigación.

Esos valores no son pura y únicamente cognitivos y, tal y como se usan en ciertos contextos de argumentación científica, de evaluación, lo que hacen es importar valores socio-políticos a esos contextos, es decir, en ciertos contextos adquieren un importante valor sociopolítico necesario para lograr un conocimiento universal y que, por consiguiente, no olvida a las mujeres y posibilita la igualdad entre los sexos. Es decir, si trabajamos con un conjunto de valores distintos, podemos captar aspectos de esa comunidad, de sus teorías y prácticas tecnocientíficas, que, de otro modo, se dejarían de lado. Podemos tener descripciones y explicaciones más ricas, «más reales». Esos valores son feministas no porque los compartan todas las mujeres, ni todas las feministas, ni siquiera porque sean apoyadas desde un grupo feminista. Son valores feministas porque contribuyen a lograr los objetivos que una feminista debe tener en filosofía de la ciencia y en ciencia. Pero también son valores que todos y todas deberíamos compartir: son deseablemente universales y pueden contribuir a lograr una ciencia mejor.

\section{REFERENCIAS BIBLIOGRÁFICAS}

ANDERSON, Elizabeth (2003): «Feminist Epistemology and Philosophy of Science», Stanford Encyclopedia of Philosophy.

ARWILL-NoRDBLADH, Elizabeth (1989): «Oscar Montelius y la liberación de las mujeres. Un ejemplo de arqueología, ideología y el primer movimiento de mujeres suecas», en Laia Colomer et al., Arqueologia y teoría feminista, Barcelona, Icaria.

BirKe, Lynda (1992): «In Pursuit of Difference: Scientific Studies of Women and Men», en Gill KIRKuP y Laurie SMITH (eds.), Inventing Women, Blackwell Pub.

BoHAn, Janis, S. ed. (1992): Re-placing women in Psychology. Readings towards a more inclusive History, Iowa, Kendall/Hunt Pub. Co.

Browne, Kingsley (1998): Divided Labours: An evolutionary view of women at work, trad. esp. Trabajos distintos. Una aproximación evolucionista a las mujeres en el trabajo, Barcelona, Crítica, 2000.

Campese, Silvia; Manuli, Paola y Sissa, Giulia (1983): Madre materia. Biología e sociología della donna antica, Turín.

FECYT (2007): Mujer y Ciencia, http://www.fecyt.es/documentos/ MUJERyCIENCIA web.pdf

GARCÍA DAUDER, Silvia (2005): Psicología y feminismo, Madrid, Narcea.

GómEZ, Amparo (2004): La estirpe maldita. La construcción científica de lo femenino, Madrid, Minerva Ed.

HAACK, Susan (2003): «Knowledge and propaganda: Reflections of an old feminist», en Cassandra PinNick, Noretta KoERTge y Robert Almeder, eds.

Horowitz, Maryanne, C. (1976): «Aristotle and Woman», Journal of the History of Biology, 9, pp. 183-213.

KoERTGE, Noretta (2003): «Feminist values and the Value of science», en Cassandra Pinnick, Noretta Koertge y Robert Almeder, eds. 
Longino, Helen (1990): Science as Social Knowledge, Princeton: Princeton University Press.

- (1994): «In Search of Feminist Epistemology», Monist 77:472-85.

- (2001): The Fate of Knowledge, Princeton, N. J.: Princeton University Press.

PÉrez SEDEÑo, Eulalia (1997): «La retórica de la ciencia y el estudio de las diferencias sexuales», Teoría. Revista de Filosofía, México, UNAM.

- (2005): «A la sombra del varón. Hijas, esposas, hermanas», en VV.AA., Mujeres sabias: entre la teoría y la práctica, Castellón de la Plana, Fundación Isonomía. www.uji.es/bin/publ/edicions/ds.pdf.

- (2005): «Objetividad y valores desde una perspectiva feminista», en N. BLÁzQuEZ y J. Flores (eds.): Ciencia, Tecnología y Género en Iberoamérica, México, CEIICH, UNAM/UNIFEM.

- (2005a): «Las ligaduras de Ulises o la supuesta neutralidad valorativa de la ciencia y la tecnología», ARBOR, vol. CLXXXI, n. ${ }^{\circ}$ 716:447-62.

- (2006): «Sexos, géneros y otras especies: diferencias sin desigualdades», en Catalina LARA (ed.) El segundo escalón. Desequilibrios de Género en Ciencia y Tecnología, Sevilla, Arcibel Eds.

PÉrez Sedeño, Eulalia y AlCAlÁ, Paloma (2006): «La Ley de la Ciencia veinte años después: ¿dónde estaban las mujeres?», en Revista Madri+D, 15 de diciembre de 2006, http://www.madrimasd.org/revista/revistaespeciall/articulos/perezalcala.asp

PinNick, Cassandra; Koertge, Noretta y Almeder, Robert, eds. (2003): Scrutinizing Feminist Epistemology: An Examination of Gender in Science. New Brunskick, N. J.: Rutgers University Press.

ScArborough, Elizabeth y Furumoto, Laurel (1987): Untold Lives: The First generation of American Women psycologyst, Nueva York, Columbia Univ. Press.

TAYLOR, Charles (1985): «Neutrality in Political Science», en Philosophy and the Human Sciences, Cambridge: Cambridge University Press.

Tiles, Mary y Hans OBerdieK (1995): Living in a Technological Culture, Londres y Nueva York, Routledge.

TANESINI, Alexandra (1999): An Introduction to Feminist Epistemologies, Blackwell Pub.

ToBach, Ethel y Rosoff, Betty (1994): Challenging Racism and Sexism: Alternatives to Genetic Explanations, Nueva York, The Feminist Press at the City of New York.

Tuana, Nancy (1993): The Less Noble Sex. Scientific, Religious and Philosophical conceptions of Woman's Nature, Bloomington, Indiana Univ. Press.

UMYC (2007): Académicas en cifras, en http://www.micinn.es/ciencia/jsp/planti1la.jsp?area $=$ umyc $\& \mathrm{id}=8$ 